\title{
USE OF MAPLE SOFTWARE TO REDUCE STUDENT TEACHERS' ERRORS IN DIFFERENTIAL CALCULUS
}

\author{
Sallah Emmanuel Kwadzo ${ }^{1}$, Joshua Kofi Sogli ${ }^{2}$ and Alex Owusu ${ }^{1}$ \\ ${ }^{1}$ Department of Mathematics, Evangelical Presbyterian College of Education, Amedzofe. \\ ${ }^{2}$ Department of Mathematics, Tarkwa Senior High School, Tarkwa
}

Cite this article:

Sallah E.K., Joshua K.S., Alex O. (2021), Use of Maple Software to Reduce Student Teachers' Errors in Differential Calculus. African Journal of Mathematics and Statistics Studies 4(3), 32-46. DOI: 10.52589/AJMSSKBCFARPR

\section{Manuscript History}

Received: 8 June 2021

Accepted: 24 Aug 2021

Published: 5 Sept 2021

Copyright $(92020$ The Author(s). This is an Open Access article distributed under the terms of Creative Commons AttributionNonCommercial-NoDerivatives 4.0 International (CC BY-NC-ND 4.0 ), which permits anyone to share, use, reproduce and redistribute in any medium, provided the original author and source are credited.
ABSTRACT: The study was conducted on the use of Maple software to reduce student teachers' errors in Differential Calculus at Evangelical Presbyterian College of Education, Volta Region - Ghana. The research design for the study was quasi-experimental non-equivalent control group design. Convenience and simple random sampling techniques were employed to obtain a sample of 104 student teachers, which comprised 53 student teachers in the control group and 51 in the experimental group. Test items were the instruments used for data gathering. Descriptive, paired samples t-test and independent samples t-test were used in analyzing data. Descriptive content error analysis revealed that student teachers committed many conceptual, procedural and technical errors when solving tasks in the differential calculus. The results also indicated that there was a statistically significant difference between student teachers' of the experimental group exposed to the use of Maple software in learning differential calculus to control groups exposed to traditional methods. Consequently, it was recommended that Maple assisted instruction be incorporated in the teaching and learning of differential calculus in the school; and also there is the need for the mathematics teachers in the school to employ blended teaching approaches, in which Maple software are used simultaneously to enhance teaching of mathematics concepts.

KEYWORDS: Errors, Maple software, Differential Calculus 


\section{INTRODUCTION}

Mathematics education is seen as the bedrock for economic, scientific and technological advancement of any progressive nation. It is for this reason that the education systems of countries that are concerned about their development lay much emphasis on the study of mathematics (Obodo, 2004; Carpenter, Franke, \& Levi, 2003).

More so, mathematics is considered as a core subject, elective subject and a screening tool for students' entry into higher education and other professions (Fletcher, 2005). In addition, this can be seen from how mathematics is applicable in our daily lives and how it forms a strong binding force among the various branches of science (Gyasi-Agyei \& Obeng-Denteh, 2014; Fletcher, 2005). It is in this vein that mathematics should be made simpler and easier for students at the pre-tertiary and tertiary levels through teaching and learning process to meet the needs of learners (Adu-Agyem \& Osei-Poku, 2012; Gyasi-Agyei \& Obeng-Denteh, 2014).

However, this was not the case at the study area of this study, as the majority of the student teachers continue to struggle to grasp the concept of differential calculus. For instance, "Differential calculus problems are really difficult; That's why we commits many errors; We don't like differential calculus; We don't know what to do with differential calculus; What relevant would differential calculus be to us; It is not an important subject because we are not going to teach it after school " were some negative statements from level 300 student teachers' of Evangelical Presbyterian College of Education who were struggling with the differential calculus course. These answers emerge from the student teachers as a result of failure of mathematics tutors at the college to explain the importance of differential calculus which includes serving as a foundation for the study of Differential Equations, Vector Analysis, Complex Analysis, and advanced mathematics etc.

Moreover, "We have poor quality of student teachers, student teachers are lazy to learn mathematics courses, students are not ready and serious about their studies' ', were some views expressed by some mathematics tutors with regards to poor performance of the student teachers in mathematics. Whilst to some extent these comments may be true, we cannot totally place the blame on student teachers alone, as it is said that the origin of students' errors are a function of many variables such as the students themselves, teachers, curriculum, and the environment. So, it is difficult to impute an error to any one variable (Brodie, 2014; Shalem, Sapire \& Sorto, 2014; Makonye, 2012).

Over the years, it is observed that there is no content error analysis on the student teachers' end of semester examination scripts during conference marking. The focus is more on the correctness or incorrectness of the answers, that is, where the student commits an error at that stage it is marked with a cross and where the correct answer is given a tick. Tutors seem less concerned about knowing the origin of student teachers' errors, as they are unable to identify, interpret, evaluate and remediate. Research shows that mathematics tutors' understanding of students' errors enhances their instructional effectiveness (Riccomini, 2005). It is also reported by Khazanov (2008) that when mathematics tutors are aware of the likely errors from a specific mathematics topic, their lesson preparations as well as their lesson evaluation strategies are sharper and addresses the students' likely errors adequately. By doing so, the students acquire the intended knowledge and skills efficiently. 
Nonetheless, the mere presence of mathematics tutors at the study area does not guarantee their effective instructions in differential calculus, as differential calculus instructions have not yet reached its full potential as observed. If the claim by some mathematics tutors that student teachers' mathematical errors are persistent, resistant and immune to instruction, and therefore distract knowledge acquisition especially in mathematics, then what hope could research in mathematical errors in differential calculus give? This has necessitated a study into the topic to find ways in which mathematics instruction at that level may be improved (Brodie, 2014).

Furthermore, the existence of open source softwares (e.g. Maple Soft, Maxima, GeoGebra, Scilab, Axiom, Geometer's Sketchpad, Mathematica, and MathLab) has enabled many in Ghana to overcome the problem of expenditure and cost (Abukari, Kuyini, \& KuyiniMohammed, 2015). One of the more prominent open-source software in the mathematics community is Maple Software (Mahmudi, 2010). Maple Software is a computer program for studying mathematics, such as functions, calculus, and matrices (Hohenwarter, Hohenwarter, Kreis, \& Lavicza, 2010). Maple software encompasses an advanced symbolic computation engine with powerful numeric algorithms, advanced visualization tools, and intuitive interfaces designed to enrich calculus teaching and learning experiences (Salleh \& Zakaria, 2016).

Moreover, Maple software provides a dynamic learning environment with more studentcentered pedagogy than traditional instruction (Milovanović, et al., 2016). The use of Maple software technology in mathematics classroom supports students in experiencing an active learning environment, in explaining some difficult concepts of calculus, in facilitating mathematical notation (Bali, Kumar, \& Nandi, 2016; Kumar, Pandey, \& Sharma, 2019; Salleh \& Zakaria, 2016; Samková, 2012; Vieira, 2015), and in promoting the visualization of scientific and mathematical concepts.

Graphical representations in mathematics (number lines, strips, graphs) which have been embedded in Maple software help students to encode and respond to general information through the visual sensory channel (Solares \& Kieran, 2013). Graphical representations assist individuals in establishing the means of solving a mathematical problem (Anderson, Lee, \& Fincham, 2014). One of the advantages of Graphical representations in mathematics was to assist the learner in understanding the concept of magnitudes as lengths, areas, and volumes (Pyke, Betts, Fincham, \& Anderson, 2015). Maple software is well suited to aid students to learn mathematics through verifying, calculating, manipulating of mathematical expressions and graphical visualization of 2D, 3D complicated graphs. Maple system uses only a procedural language of 4th generation (4GL), similar to the C language, FORTRAN, BASIC and Pascal. Tedious computations are performed by Maple software by featuring systematic solutions of the problem as obtained when done manually (Bali, Kumar, \& Nandi, 2016).

In addition, scholarly articles available have provided evidence of Maple software's potential as an instructional medium. However, they offered less information on visualization in the teaching of differential calculus at the colleges of education in Ghana (Buneci, 2014). Jahanshahi, Babolian, Torres, and Vahidi, (2015), in their study, detailed the use of the trapezoidal rule and Maple to solve, numerically, Abel integral equations of the first kind. Moreover, Yurttas, Ozgur, and Cangul, (2012) asserted that Maple was an efficient tool to calculate the Minimal Polynomial of $2 \cos (\pi / n)$ over the set of rational numbers.

Moreover, learners can make the most of available technology such as Maple Software, GeoGebra, Geometer's Sketchpad, Mathematica, and MathLab. Technology is relevant 
because it acts as an educational object that influences learning content and goals, as well as a means for enhancing the teaching and learning process (Tang \& Austin, 2009).

In contrast, "Some years ago, technology was not used in teaching yet understanding of mathematical concepts was high among A \& O level students. The use of technology will impair student teachers' mathematical ability and result in increased mathematics illiteracy; Student teachers will become lazy in the college" were some misconceptions held by some mathematics tutors with regards to the use of technology in teaching and learning of the mathematics courses at the college.

Notwithstanding, the numerous changes to the old curriculum by the Anamuah-Mensah Educational Review Committee, teaching and learning of mathematics courses including differential calculus have been characterized by rote memorization approaches at the college which result in increased mathematical errors committed by student teachers. In Ghana, the use of technology in education is still uncommon, as few people working in the field of mathematics education at the college of education level are unaware of the rapid expansion of computer technologies in recent years for teaching, learning and research in the field.

Nevertheless, there is a growing body of research that suggests its extended use is imminent (Salleh \& Zakaria, 2016; Usman, 2012; Mahir, 2009; Abdul Rahman, 2005).

The teaching technique has been improved by incorporating Maple software technology, which allows students to explore differential calculus in the learning process. Maple software was chosen for the study because it is well suitable for a variety of uses including solving differential calculus problems. Furthermore, it requires minimum programming skills as compared to other mathematical softwares. Considering the importance of this subject in academic undertaking, it was deemed necessary to use Maple software to reduce student teachers' errors in differential calculus.

\section{Theoretical Framework}

Addressing students' errors in differential calculus through the integration of Maple software in teaching and learning drew its theoretical framework from constructivism. Constructivism advocates learner-centered, activity-centered interactive pedagogical approach thus emphasize the importance of the learner being actively involved in the learning process, Studies have shown that the constructivism theory is effective in a computer-technology-integrated environment (Kumar, Pandey, \& Sharma, 2019; Bali, Kumar, \& Nandi, 2016; Salleh \& Zakaria, 2015). With technology, students are flexible in adjusting their learning strategy based on their learning style. The researcher based the development of the study on a constructivism theory of Action, Process, Object and Schema - Activities using Maple software on the computer, Classroom discussion based on Maple outputs, and Exercises done outside the class hour known in short as APOS - ACE theory

\section{Conceptual Framework}

Considering the type of research that was undertaken, research questions, and category of data collected. The study was modeled by a conceptual framework, which depicted a representation of dependent and independent variables and the relationships between them. 


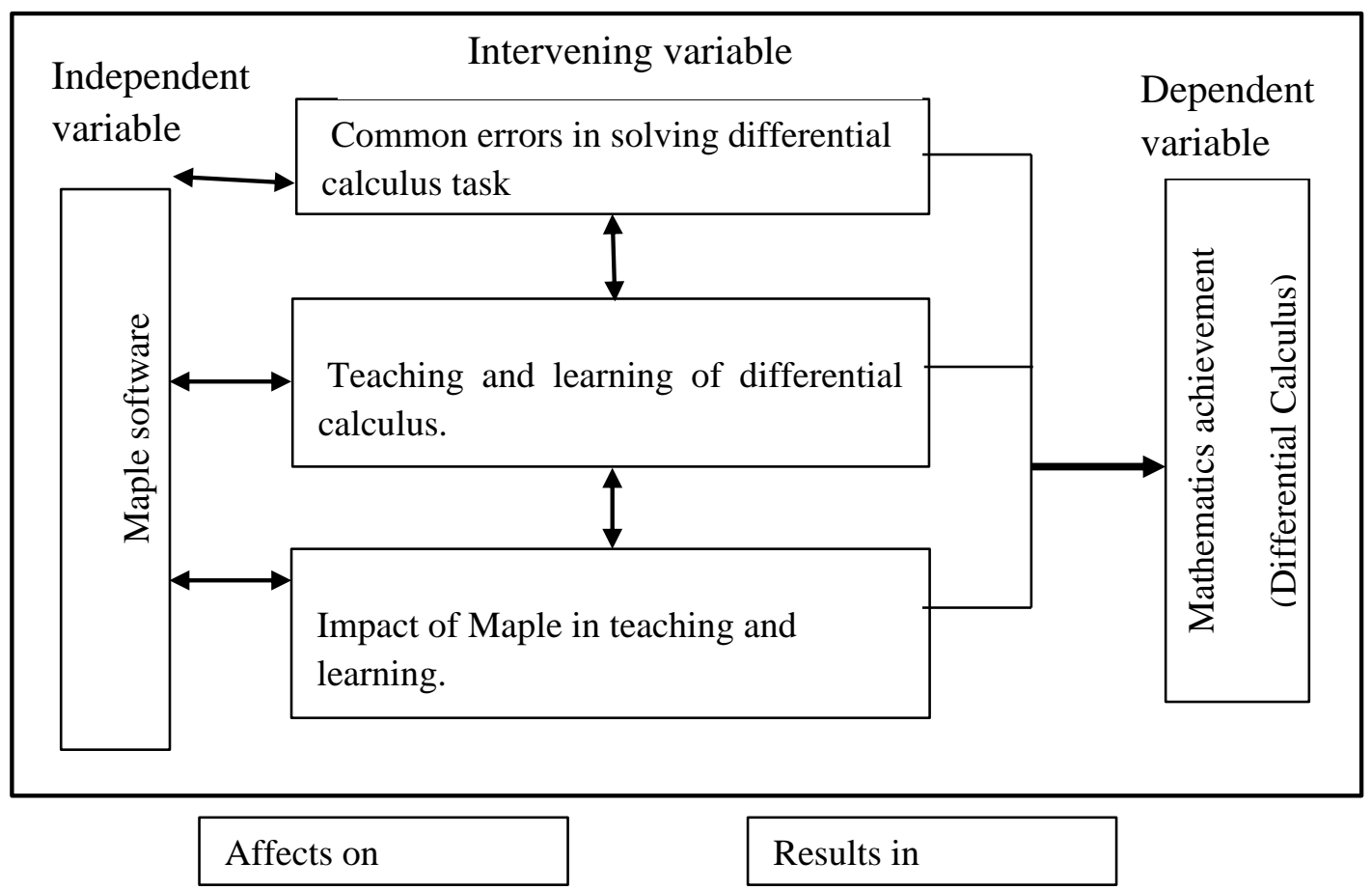

Figure 1 Conceptual Framework Model of the Study

From figure 1, the independent variable (Maple software) will affect student teachers' common errors in solving differential calculus tasks. Maple software will also affect the teaching and learning of differential calculus, as well as impacts of Maple in teaching and learning of differential calculus. The expected outcome will be a change (positive or negative) in the dependent variable (Differential Calculus) depending on the outcome of the study

\section{Purpose of the Study}

The purpose of the research was to analyze student teachers' errors in differential calculus and the impact of Maple integration in teaching and learning of differential calculus.

\section{Objectives of the Study}

The following were the objectives of the study:

1. To identify common errors that emerge from student teachers' responses to calculus tasks?

2. To determine the impact of Maple software on student teachers' understanding of calculus? 


\section{Research Questions}

The following research questions were formulated to guide the study:

1. What common errors emerge from student teachers' responses to calculus tasks?

2. What is the impact of Maple software on student teachers' understanding of calculus?

\section{Hypothesis of the Study}

$\mathrm{H}_{0}$ : There is no statistically significant difference between the mean scores of the control and experimental group in the post-test.

\section{METHODOLOGY}

\section{Method}

The study followed Creswell (2014) description of quasi-experiment non-equivalent control group design. This quasi-experiment of causal comparison is most ideal for investigating the effectiveness of an intact group intervention (teaching strategy), as it is regarded as the gold standard casual design because it is strong against internal validity. When there are at least two compare groups, the quasi-experimental design fulfills the criterion of a strong research methodology: one-control group and one treatment group (Figure 2).

$\begin{array}{lccc}\text { Types of groups } & \text { pretest } & \text { treatment } & \text { pos } \\ \text { Experimental } & \mathrm{O}_{1} & \mathrm{X} & \mathrm{O}_{3} \\ \text { Control } & \mathrm{O}_{2} & \mathrm{Y} & \mathrm{O}_{4}\end{array}$

The pretests $\left(\boldsymbol{O}_{1}\right.$ and $\left.\boldsymbol{O}_{2}\right)$ were done to determine the initial entry points and compare differences between groups before treatment. The posttests $\left(\boldsymbol{O}_{3}\right.$ and $\left.\boldsymbol{O}_{4}\right)$ were administered to examine the treatment effect after the experimental group received differential calculus tuition through Maple instruction $(\boldsymbol{X})$ and the control group received differential calculus tuition through the conventional instruction $(\boldsymbol{Y})$.

The convenience sampling technique was used in selecting a sample of 104 student teachers due to accessibility, geographical proximity, availability and willingness to participate in the study. Simple random sampling technique was also used in categorizing them into a control group of 53 student teachers and an experimental group of 51 respectively.

The instrument used to measure student teachers' understanding in differential calculus was calculus achievement tests. The instrument was developed and carefully piloted at the University of Cape Coast Distance Education, Jasikan Learning Centre in Oti Region of Ghana to ensure its reliability and validity. By using KR21 formula, the reliability of the test instrument (pretest and posttest) was proven high with reliability estimates of (0.69 and 0.73$)$. The content validity was established by matching the test questions to specific objectives as stated in their course manual. 
The two groups were taught by the researchers for both lecture and tutorial slots. Maple software was used to develop a lesson module for the experimental group based on Dubinsky's APOS - ACE theory (Dubinsky and McDonald, 2001) which consists of three parts: Activity using Maple software, Class discussion based on Maple outputs, and Tutorial Exercises outside class hour. The researchers evaluated the content and tutorial questions in the lecture room, and Maple-integrated activities and Maple procedural output were carried out in the college computer laboratory; where students explored the activities developed using Maple software.

The teaching approach used in the control group stressed the fluency of the process in solving differential calculus concepts. The solutions to sample questions were discussed, and summarized by highlighting the pattern of steps involved in each differential calculus concept, so that the students could memorize them. The tutorial sessions for the control group were conducted in the normal classroom. During the tutorial sessions, they discussed problems they encountered with the researchers. This discussion was done without any help from any mathematical software. The medium used during the tutorial sessions were pen and paper only.

\section{RESULTS/FINDINGS AND DISCUSSION}

Research question 1 focuses on errors student teachers' commit in solving differential calculus tasks. A descriptive content error analysis of pretest results of groups was made under the following sub-topics of differential calculus:

(i) Derivative of function from the first principle $\frac{d y}{d x}=\frac{f(t+h)-f(t)}{h}$.

$$
\text { Derivative of a function using the power rule } \frac{d\left(a x^{n}\right)}{d x}=n a^{n-1} \text {. }
$$

(iii) Derivative of a function involve applying the quotient rule $\frac{d y}{d x}=\frac{v \frac{d u}{d x}-u \frac{d v}{d x}}{v^{2}}$.

The content error analysis helped to make inferences about the student teachers' errors in the scripts. The intentions of the students were interpreted and trends in errors became discernible. The results on the table 1 to 3 show descriptive performance of student teachers in solving the differential calculus tasks.

\section{Content error analysis of derivative from first principle of the function $f(t)=\sqrt{t}$}

Item question 1 tested student teachers to determine the $f^{I}(t)$ from the first principle of the function of $(t)=\sqrt{t}$. The main errors that student teachers displayed on this question were failure to operationalize the functional notation through proper substitution of the point $f(t+h)-f(t)=\sqrt{t+h}-\sqrt{t}$ in the range. This failure could be borne from the formula function concept image that student teachers' loosely held. The student teachers displayed a conceptual error as they failed to make proper substitution or missed the first step of finding derivative from first principle of forming the difference $f(t+h)-f(t)=\sqrt{t+h}-\sqrt{t}$. Most of them had this expression $f(t+h)-f(t) \leftarrow(t+h)-(t), \quad f(t+h) \leftarrow f t+$ $f h, f(t+h)+f(t)=\sqrt{t+h}+\sqrt{t}$. 
Error such as equal sign $(=)$ which shows the link between expressions was completely missing. Also, students had $(t+h)-(t)$ instead of this $\sqrt{t+h}-\sqrt{t}$ indicating an error of radical sign completely missing or improper substitution into $f(t+h)-f(t) . f(t+h) \leftarrow f t+f h$, this is what the researcher refers to as an algebraic multiplication frame. The student teachers reverted to this frame because it is algebraically correct, but in the sense of differentiable functions, it was not. $f(t+h)+f(t)=\sqrt{t+h}+\sqrt{t}$, minus instead of a plus required to denote the infinitesimal change in the mantissa. This could be related to undifferentiated binary operation frames. This frame ignores other operation signs and always adds. It is observed that student teachers' did not know or understand the definition of the differential of a function, a concept that was necessary to answer this question. Some student teachers were confused by the notation $f(t)$ and $f^{I}(t)$ failing to distinguish between them. At the same time many student teachers used them interchangeably. Notation is closely tied to calculus concepts, and any failure to understand notation resulted in procedural errors and failure to work out calculus tasks.

In addition, student teachers had the difficulties of dividing by " $h$ " to obtain gradient function of $\frac{f(t+h)-f(t)}{h}=\frac{\sqrt{t+h-} \sqrt{t}}{h}$ which by rationalization of numerator $\frac{(\sqrt{t+h}-\sqrt{t})(\sqrt{t+h}+\sqrt{t})}{h(\sqrt{t+h}+\sqrt{t})}$. Many student teachers exhibited primitive knowledge gaps in algebraic knowledge under surds. These student teachers hold the misconception of only rationalizing denominator approach of radicals $\frac{(\sqrt{t+h}-\sqrt{t})}{h} \times \frac{h}{h}$. The few that had rationalization of radical approach correctly applying the limit as" $h$ " tends to zero $\frac{f(t+h)-f(t)}{h}=\frac{1}{(\sqrt{t+h}+\sqrt{t})}=\frac{1}{2 t}$ wrongly. Also $\frac{d y}{d x}$ and limit operator $\lim _{h \rightarrow 0}$ symbols were omitted in the solutions presented by the student teachers. The errors related to symbols and variables pertaining to differential calculus might seem trivial but not. Table 1 describes statistically the performance of each skill under derivative of a function from the first principle.

Table 1: Derivatives using First Principles' Test Items Results

\begin{tabular}{|c|c|c|c|c|c|}
\hline \multicolumn{2}{|c|}{ Ability to: } & & \multirow{2}{*}{$\begin{array}{c}\text { Number of } \\
\text { students with } \\
\text { correct } \\
\text { answers } \\
56(53.85)\end{array}$} & \multirow{2}{*}{$\begin{array}{c}\begin{array}{c}\text { Number of } \\
\text { students with } \\
\text { wrong answers }\end{array} \\
40(38.46)\end{array}$} & \multirow{2}{*}{$\begin{array}{c}\text { Number } \\
\text { that failed } \\
\text { to } \\
\text { attempts }\end{array}$} \\
\hline i. & $\begin{array}{l}\text { Form the difference } f(t+ \\
h)-f(t)\end{array}$ & & & & \\
\hline ii. & $\begin{array}{l}\text { Divide by " } h \text { " to obtain the } \\
\text { gradient function } \\
\underline{f(t+h)-f(t)}\end{array}$ & 104 & 19(18.27) & $77(74.04)$ & $8(7.69)$ \\
\hline iii. & $\begin{array}{l}\frac{h}{\text { Apply the limit as " } h "} \\
\text { tends to zero } \frac{f(t+h)-f(t)}{h}\end{array}$ & 104 & $4(3.85)$ & $92(88.46)$ & $8(7.69)$ \\
\hline
\end{tabular}


The result from Table 1 suggests that student teachers lack both conceptual and procedural knowledge of differential calculus in finding the derivative of the function using the first principle approach. Student teachers confirmed that some of the errors are caused by the course tutor's approach of just wanting them to memorize formulas without explaining the meaning of the formulas. These findings are in line with a report from Siyepu (2013) differential calculus requires a high level of conceptual understanding and lack of conceptual knowledge of differential calculus can challenge and limit students when learning other related science applications. NTCM (2014) argues that procedural knowledge should build on conceptual knowledge. The findings reveal that student teachers lacked both, which contributed to their errors when solving differential calculus tasks. The researcher agrees with these earlier researchers that mathematics tutors can cause the lack of conceptual knowledge of students in differential calculus (Muzangwa \& Chifamba, 2012; Coe, 2007; Ubuz, 2007).

From the result it is revealed that these student teachers show an inadequate understanding of the concepts of functions and limits. The findings agree with Muzangwa and Chifamba (2012). They argued that studying students' errors and misconceptions in differential calculus showed that the errors in differential calculus are caused by knowledge gaps of basic functions and limits.

Content error analysis of differentiating a function using the power rule $y=\frac{8 x^{\frac{3}{2}-} 6 x^{\frac{5}{2}}}{2 \sqrt{x}}$

The second task required student teachers to differentiate a function of $=\frac{8 x^{\frac{3}{2}}-6 x^{\frac{5}{2}}}{2 \sqrt{x}}$. This task was completely algebraic; simplifying the expression $y=\frac{8 x^{\frac{3}{2}-}-6 x^{\frac{5}{2}}}{2 \sqrt{x}}=\frac{8 x^{\frac{3}{2}-}-6 x^{\frac{5}{2}}}{2 x^{\frac{1}{2}}}=4 x^{\frac{3}{2}-\frac{1}{2}}-$ $3 x^{\frac{5}{2}-\frac{1}{2}}=4 x-3 x^{2}$ so that its terms would be in a form, which the power rule of approach of finding derivative could be applied easily; that is the terms of $x$ must be re-expressed free from radicals and reciprocals. The first stage of the error was in algebraic procedure to convert $\frac{8 x^{\frac{3}{2}}-6 x^{\frac{5}{2}}}{2 \sqrt{x}}=\frac{8 x^{\frac{3}{2}-} 6 x^{\frac{5}{2}}}{2 x^{\frac{1}{2}}}$, the student teachers failed recognize that algebraic manipulation of $2 \sqrt{x}$ $=2 x^{\frac{1}{2}}$, as some student teachers avoided the radical sign completely to have $2 x$, and others also used the denominator of powers to cancelled out it whole part to have $4 x^{3}-3 x^{5}$, to avoid fractional powers. The second stage of the error was concerned with applying the law of indices to simplify $\frac{8 x^{\frac{3}{2}-}-6 x^{\frac{5}{2}}}{2 x^{\frac{1}{2}}}=4 x^{\frac{3}{2}-\frac{1}{2}}-3 x^{\frac{5}{2}-\frac{1}{2}}$ to have $4 x-3 x^{2}$. Student teachers had difficulties in applying the concept of indices, as some simplify the expression $\frac{8 x^{\frac{3}{2}}-6 x^{\frac{5}{2}}}{2 x^{\frac{1}{2}}}=\frac{(8 x-6 x)^{\frac{3}{2}-\frac{5}{2}}}{2 x^{\frac{1}{2}}}=$ $\frac{2 x^{\frac{-2}{2}}}{2 x^{\frac{1}{2}}}=\frac{2 x^{-1}}{2 x^{\frac{1}{2}}}$. This showed a lack of mastery of the work on exponents. The third stage of the error was concerned with applying the power rule to differentiate $4 x-3 x^{2}=4-6 x$, which did not go well with those who had the algebraic procedures correctly. 
Table 1: Derivatives using Rules of Differentiation Test Items' Results

\begin{tabular}{|c|c|c|c|c|c|}
\hline Ability to: & & $\mathrm{N}$ & $\begin{array}{c}\text { Number of } \\
\text { students with } \\
\text { correct } \\
\text { answers }\end{array}$ & $\begin{array}{c}\text { Number of } \\
\text { students with } \\
\text { wrong answers }\end{array}$ & $\begin{array}{l}\text { Number } \\
\text { that failed } \\
\text { to } \\
\text { attempts }\end{array}$ \\
\hline i. & $\begin{array}{l}\text { Transform the function } \\
\text { algebraically }\end{array}$ & 104 & $60(57.69)$ & $38(36.54)$ & $6(5.77)$ \\
\hline ii. & $\begin{array}{l}\text { Apply the concept of } \\
\text { indices }\end{array}$ & 104 & $32(30.77)$ & $66(63.46)$ & $6(5.77)$ \\
\hline iii. & $\begin{array}{l}\text { Apply the power rule of } \\
\text { differentiation }\end{array}$ & 104 & $11(10.58)$ & $87(83.65)$ & $6(5.77)$ \\
\hline
\end{tabular}

From Table 2, It was clear that student teachers' poor performance in this differential calculus task is entangled in algebra. Those student teachers who did not have fluency in algebra struggled to solve the differential calculus task. Algebra Literacy ought to be researched and findings urgently applied to the teaching and learning of mathematics if learners are to begin to learn and understand mathematics and calculus and therefore science and technology (Salazar, 2014; Yee \& Lam, 2008; Kiat, 2005).

Content error analysis of differentiating a function using the quotient rule $\frac{\sin x+\cos x}{\sin x-\cos x}$

The third errors analysis was in derivative of trigonometric function $\frac{\sin x+\cos x}{\sin x-\cos x}$. Errors displayed by student teachers were failure to grasp derivative concepts of quotient function $y=\frac{u(x)}{v(x)}$ given by rule $\frac{d y}{d x}=\frac{v \frac{d u}{d x}-u \frac{d v}{d x}}{v^{2}}$ in the given problem. Few students had quotient rule correctly but were confused with derivative of trigonometric functions, as student teachers recall the derivative of trigonometric functions of $u(x)=\sin x+\cos x \rightarrow \frac{d u}{d x}=-\cos x+\sin x, v(x)=$ $\sin x-\cos x \rightarrow \frac{d v}{d x}=\cos x-\sin x$, instead of $u(x)=\sin x+\cos x \rightarrow \frac{d u}{d x}=\cos x-\sin x$, $v(x)=\sin x-\cos x \rightarrow \frac{d v}{d x}=\sin x+\cos x$. The few students who recall the derivatives correctly demonstrated procedural errors of not carry out correct manipulations or algorithms $\frac{\left(\sin ^{2} x+\cos ^{2} x\right)-\left(\sin ^{2} x+\cos ^{2} x\right)}{\sin ^{2} x-\cos ^{2} x}$ instead of $\frac{-(\sin x-\cos x)^{2}-(\sin x+\cos x)^{2}}{(\sin x-\cos x)^{2}}$. It was clear that student teachers exhibited primitive knowledge gaps in algebraic knowledge concerning multiplication of binomials, handling of indices as well as simplification of trigonometric functions. These concepts were lacking in the solutions presented by the majority of the student teachers. In addition, $\frac{d y}{d x}$ the symbol was omitted in the solutions presented by the student teachers. The errors related to symbols and variables pertaining to differential calculus might seem trivial but not. 
Table 3: Derivatives of Trigonometric Function Test Items' Results

\begin{tabular}{|c|c|c|c|c|}
\hline Ability to: & $\mathrm{N}$ & $\begin{array}{l}\text { Number of } \\
\text { students } \\
\text { with correct } \\
\text { answers }\end{array}$ & $\begin{array}{l}\text { Number of } \\
\text { students with } \\
\text { wrong } \\
\text { answers }\end{array}$ & $\begin{array}{l}\text { Number } \\
\text { that failed to } \\
\text { attempts }\end{array}$ \\
\hline $\begin{array}{l}\text { i. State the derivative rule of } \\
\text { quotient function } y=\frac{u(x)}{v(x)}\end{array}$ & 104 & $33(31.73)$ & $51(49.04)$ & 20(19.23) \\
\hline $\begin{array}{l}\text { ii. Apply the rule of } \\
\text { differentiate the } \\
\text { trigonometric functions of } \\
u(x)=\sin x+\cos x \\
\text { and } v(x)=\sin x-\cos x\end{array}$ & 104 & $19(18.27)$ & $65(62.50)$ & $20(19.23)$ \\
\hline $\begin{array}{l}\text { iii. Proper substitution and } \\
\text { simplification into the } \\
\text { function } y=\frac{u(x)}{v(x)}\end{array}$ & 104 & $6(5.77)$ & $78(75)$ & $20(19.23)$ \\
\hline $\begin{array}{l}\text { Write the correct answer } \\
\text { with the } \frac{d y}{d x} \text { attached }\end{array}$ & 104 & $2(1.92)$ & $82(78.85)$ & $20(19.23)$ \\
\hline
\end{tabular}

Percentages in parentheses

Based on Table 3, there is evidence that student teachers wrongly apply the rule of finding derivatives of trigonometric function and also, in doing algebraic manipulations. Usman and Hussaini (2017) report that, the most frequent errors made by students in solving derivative problems involving trigonometry, are errors of understanding, transformation errors, and process skill errors. This may be due to the lack of emphasis by the teacher in teaching the simplification of concepts. In addition, these errors occur because students only memorize the trigonometry formula. Chigonga (2016) reports that one of the causes of students having difficulty in solving derivatives involving trigonometric functions is because they do not master both conceptual and procedural knowledge. Therefore, we need to review trigonometric learning before teaching calculus, so that the possible errors or misunderstandings of students can be overcome.

Research Question on impact of the Maple software on student teachers' understanding of differential calculus. The mean scores of both groups in the pretest and posttest were compared using the paired sample t-test. The results of the analysis for the control and experimental groups were summarized in tables 4 and 5 respectively.

Table 4: Paired Samples T- test of Posttest and Pretest Scores of Experimental Group.

\begin{tabular}{llllrrrr}
\hline Group & Test & N & Mean & SD & df & t-value & p-value \\
\hline Experimental & Post-test & 51 & 37.15 & 6.41 & 50 & & \\
& & & & & & -10.14 & 0.00 \\
Experimental & Pre-test & 51 & 13.68 & 8.42 & 50 & & \\
\hline
\end{tabular}


A paired sample t-test was carried out which compared the mean difference of posttest and pretest scores of the experimental group as the data met all the assumptions of paired sample t-test. The result verify mean difference between the posttest and pretest scores indicated that there was a significant improvement in the achievement of posttest scores $[\mathrm{M}=37.15, \mathrm{SD}=$ 6.41] over pretest scores $[\mathrm{M}=13.68, \mathrm{SD}=8.42]$ at $\alpha<0.05$ level of significance, with conditions $[\mathrm{t}(50)=-10.14, \mathrm{P}=0.00]$. It was therefore concluded that there was a statistically significant difference between the posttest and pretest scores of students when taken through differential calculus using Maple software as teaching and learning tool. These findings are in line with reports from Bogomolova (2015); Cao, (2015); Prince and Flek, (2014) and Larson and Edward (2013) that Maple software is easy to learn and use, as it requires minimum programming as compared to other mathematical software. They also reported that Maple software was designed to make it easily accessible and an automation of computations as mathematics students offload their computation load to the system without compromising the mathematical understanding. Table 5 showed paired sample t-test of posttest and pretest scores of the control group.

Table 5: Paired Samples T- test of Posttest and Pretest Scores of Control Group

\begin{tabular}{llllcccc}
\hline Group & Test & N & Mean & SD & df & t-value & p-value \\
\hline Control & Post-test & 53 & 22.78 & 5.63 & 52 & & \\
& & & & & & -8.91 & 0.00 \\
Control & Pre-test & 53 & 17.72 & 7.35 & 52 & & \\
\hline
\end{tabular}

The results on Table 5 showed that there was no statistically significant difference of the pretest scores $[M=17.72, S . D=7.35]$ against posttest scores $[M=22.78, S . D=5.63]$ at $[t(52)=-$ $8.91, \mathrm{P}=0.00]$. The traditional method of teaching seems not to produce significant difference as compared to Maple software approach of teaching differential calculus. This was because the mean difference of 5.06 showed that the control group exposed to the traditional method teaching was not very good in the understanding of differential calculus concepts. Poor understanding of pre - requisite concepts, memorization of differential calculus formulas and tutor centered approach of teaching are some of the contributing factors to these low performances in differential calculus achievement tests. These findings confirmed reports of Salazar, (2014) and Yee and Lam, (2008) that the teacher centered teaching approach appears to be contributing insignificantly to the performance in the differential calculus. Student teachers felt that the approaches used by the mathematics tutors were a challenge to them. They concurred that tutors just taught them the procedures without explaining their meanings. Axtell (2006) argues that the calculus curriculum needs to be revised to improve teaching and learning that focuses on both conceptual and procedural understanding. Lloyd-Smith (2010) argued that blended instruction offers more choices for content delivery and is more effective than teaching that is fully online or fully classroom based. Garnham and Kaleta (2002) reported that students learn more in blended learning environments than they do in comparable traditional classes. 
Table 6: Independent samples t-test of Posttest of Control and Experimental Groups

\begin{tabular}{llllcccc}
\hline Group & Test & N & Mean & SD & df & t-value & p-value \\
\hline Control & Post-test & 53 & 22.78 & 5.63 & & & \\
& & & & & 101 & -12.43 & 0.00 \\
Experimental & Post-test & 51 & 35.15 & 6.41 & & & \\
\hline
\end{tabular}

The independent samples t-test indicates that there was statistically significant difference between the post- test mean scores of the experimental group $[\mathrm{M}=35.15, \mathrm{SD}=6.41]$ and the control group $[\mathrm{M}=22.78, \mathrm{SD}=5.63], \mathrm{t}(101)=-12.43$. In the analysis, the difference was significant at $5 \%$ with a p-value of 0.00 which is less than the significance level $(0.00<0.05)$, indicating a significant difference between the mean scores of the control and the experimental groups. The mean of the experimental group $[\mathrm{M}=35.15, \mathrm{SD}=6.41]$ is significantly higher than the mean of the control group $[\mathrm{M}=22.78, \mathrm{SD}=5.63]$ in the post-test. As a result, the null hypothesis, "there is no statistically significant difference between the mean scores of control and experimental groups in the post test" was rejected. In effect, the alternative hypothesis "there is a statistically significant difference between the mean scores of control and experimental groups in the post test" was retained. The integration of Maple activities in differential calculus tutorial classes was found to give positive effects on enhancing student teachers' understanding in this topic. These values show that the integration of Maple software in the learning of differential calculus has made a significant contribution to the effectiveness of differential calculus teaching for the student teachers. The findings agree with those of Karper, Robinson and Casado-Kehoe, (2013) that students taught with CAI packages in Chemistry, Mathematics and Education in general, perform better than those taught with normal classroom instruction.

\section{CONCLUSION/ FUTURE RESEARCH}

The study focused on how to use Maple as a learning tool to reduce student teachers' errors in differential calculus. The findings revealed that student teachers performed poorly in finding the derivatives. The poor performance was possibly due to the tutors' teaching approaches and student teachers' lack of procedural and conceptual knowledge. The integration of Maple activities in teaching and learning differential calculus was found to give positive effects on student teachers' understanding of differential calculus.

The study therefore recommends Maple assisted instruction in the teaching and learning of differential calculus, and the need for mathematics tutors at all the College of Education in the tertiary education system to integrate the blended teaching and learning methods, in which computer software such as Maple software are used simultaneously to enhance mathematics instruction. 


\section{REFERENCES}

Abdul - Rahman, S. (2005). Learning with examples and students' understanding of integration. Proceedings of the Eighth International Conference of Mathematics Education into the 21st Century Project on Reform, Revolution and Paradigm Shifts in Mathematics Education (pp. 16(2), 144-151). Malasia: Johor Bahru Press.

Abukari, Z., Kuyini, A. B., \& Kuyini-Mohammed, A. (2015). Education and health care policies in Ghana: examining the prospects and challenges of recent provisions. Sage Open, 5(4), 215228.

Adu-Agyem, J., \& Osei-Poku, P. (2012). Quality education in Ghana: The way forward. International Journal of Innovative Research and Development (ISSN 2278-0211), 1(9), 164-177.

Anderson, J. R., Lee, H. S., \& Fincham, J. M. (2014). Discovering the structure of mathematical problem solving. NeuroImage, 97, 163-177.

Axtell, M. (2006). A two- semester precalculus/calculus sequence:A Case study. Mathematics and Computer Education, 40(2),130-137.

Bali, J. S., Kumar, A., \& Nandi, V. (2016). An experience, using software based tools for teaching and learning mathematically intensive signal processing theory concepts. Innovation and Technology in Education (MITE), 100-104.

Brodie, K. (2014). Learning about learner errors in professional learning communities. Educational Studies in Mathematics, 85, 221-239.

Buneci, M. R. (2014). Using Maple to represent the subgroupoids of trivial groupoid $\mathrm{x} \times \mathrm{z} \times \mathrm{x}$. Fiability \& Durability / Fiabilitate Si Durabilitate, (1), 446-454.

Carpenter, T. P., Franke, M. L., \& Levi, L. (2003). Thinking mathematically. Portsmouth, NH: Heinemann.

Chrysanthou, I., Hohenwarter, J., Hohenwarter, M., Hreinsdóttir, F., Kreis, Y., Lavicza, Z., et al. (2010). First International GeoGebra Conference 2009. Hagenberg.

Creswell, J. W. (2014). Research Design: Qualitative, Qualitative and Mixed Methods Approaches (4th ed). Lincoln: Sage Publications.

Dubinsky, E., \& McDonald, M. A. (2001). APOS:Constructivist theory of learning in undergraduate mathematics research. Netherlands: Kluwer Academic Publishers.

Fletcher, J. A. (2005). Constructivism and mathematics education in Ghana. Mathematics connection, 5, 29-36.

Gyasi-Agyei, K. A., Gyasi-Agyei, A., \& Obeng-Denteh, W. (2014). Mathematical modeling of the epidemiology of tuberculosis in the Ashanti region of Ghana. Journal of Advances in Mathematics and Computer Science, 375-393.

Jahanshahi, S., Babolian, E., Torres, D. F., \& Vahidi, A. (2015). Original article: Solving Abel integral equations of the first kind via fractional calculus. Journal of King Saud University Science, 27,161-167.

Khazanov, V. (2008). Misconceptions in probability. Journal of Mathematical Sciences, 141(6), 1701-1701.

Kumar, K., Pandey, R. K., \& Sharma, S. (2019). Approximations of fractional integrals and Caputo derivatives with application in solving Abel's integral equations. Journal of King Saud University-Science, 31(4), 692-700.

Mahir, N. (2009). Conceptual and procedural performance of undergraduate students in integration. International journal of Mathematics Education in Science and Technology, 40(2), 201-211.

Mahmudi, A. (2010). Membelajarkan geometri dengan program GeoGebra. Seminar Nasional Matematika dan Pendidikan Matematika , 469-477. 
Makonye, J. (2012). Learner errors on calculus tasks in the NSC examinations: Towards an analytical protocol for learner perturbable concepts in introductory differentiation. The International Journal of Learning, 18(6), 339-357.

Milovanović, M., Perišić, J., Vukotić, S., Bugarčić, M., Radovanović, L., \& Ristić, M. (2016). Learning mathematics using multimedia in engineering education. Acta Technica Corviniensis-Bulletin Of Engineering, 9(1), 45-49.

Obodo, G. C. (2004). Principles and practice of mathematics education in Nigeria. Academic Forum (pp. 2-7). Enugu: Organizers of Academic Forum.

Prince, T., \& Flek, R. (2014). Developing and teaching an honors Calculus course in a community college. International Journal of Mathematics Education, 39(4), 297-300.

Pyke, A., Betts, S., Fincham, J. M., \& Anderson, J. R. (2015). Visuospatial referents facilitate the learning and transfer of mathematical operations: Extending the role of the angular gyrus. Cognitive, Affective and Behavioral Neuroscience, 15(1), 229-252.

Riccomini, P. (2005). Identification and remediation of systematic error patterns in subtraction. Learning Disability Quarterly, 28(3), 233-242.

Salazar, D. (2014). Salazar's Grouping Method: Effects on Students' Achievement Integral Calculus. Journal of Education and practice, 5(15),119-126.

Salleh, T. S., \& Zakaria, E. (2016). The Effects of Maple Integrated Strategy on Engineering Technology Students' Understanding of Integral Calculus. Turkish Online Journal of Educational Technology-TOJET, 15(3), 183-194.

Samková, L. (2012). Calculus of one and more variables with Maple. International Journal of Mathematical Education In Science \& Technology, 43(2), 230-244.

Shalem, Y., Sapire, I., \& Sorto, M. (2014). Teachers' explanations of learners' errors in standardised mathematics assessments. Pythagoras, 254, $11-17$.

Siyepu, S. (2013). An exploration of students' errors in derivatives in a university of technology. Journal of Mathematical Behavior, 32(3), 577-592.

Solares, A., \& Kieran, C. (2013). Articulating syntactic and numeric perspectives on equivalence: The case of rational expressions. Educational Studies In Mathematics, 84(1), 115-148.

Tang, T. L., \& Austin, M. J. (2009). Students' perceptions of teaching technologies, application of technologies, and academic performance. Computers \& education, 53(4), 1241-1255.

Ubuz, B. (2007). Interpreting a graph and constructing its derivative graph: Stability and change in students' conceptions. International Journal of Mathematical Education in Science and Technology, 38(5), 609-637.

Usman, A. (2012). Analysis of Algebraic Errors in Applied Calculus Problem Solving. 12th International Mathematics congress on Mathematics Education, COEX (pp. 42, 165-177). Korea: Seoul Press.

Vieira, A. F. (2015). Viewing the roots of polynomial functions in complex variables: The use of GeoGebra and the CAS Maple. Acta Didactica Napocensia , 6(4), 45-58.

Yee, N. K., \& Lam, T. T. (2008). Pre-University Students' Errors in Integration of Rational Functions and Implications for Classroom Teaching. Journal of Science and Mathematics Education in Southeast Asia, 31(2), 100-116.

Yurttas, A., Ozgur, B., \& Cangul, I. N. (2012). Calculation of the minimal polynomial of $2 \cos (\pi / \mathrm{n})$ over Q with Maple. Numerical Analysis and Applied Mathematics ICNAAM, 1479, 371-374.

Zakaria, E., \& Salleh, T. S. (2015). Using technology in learning integral calculus. Mediterranean Journal of Social Science, 6(5),144. 